\title{
Lasalocida Sódica Suplementada Via Sal para Fêmeas de Corte Mantidas em Pastagem Cultivada de Estação Fria
}

\author{
Cledson Roso', João Restle ${ }^{2}$
}

\begin{abstract}
RESUMO - Este experimento foi conduzido para avaliar o efeito da lasalocida sódica adicionada ao sal comum e usada como suplemento, no desempenho de fêmeas de corte, com idade de 10 meses e peso médio inicial de $200 \mathrm{~kg}$, mantidas em pastagem cultivada com gramíneas anuais de estação fria. A semeadura, a lanço, foi realizada em 21/04/95, sendo a área adubada com 200 kg/ha (05-30-15). A adubação de cobertura foi de $175 \mathrm{~kg} / \mathrm{ha}$ de nitrogênio, na forma de uréia e parcelada em quatro aplicações. O estabelecimento da pastagem ocorreu de 21/04 a 08/06 e o período experimental iniciou em 08/09, estendendo-se até 14/11. O sal e a mistura de sal mais lasalocida foram fornecidos semanalmente. A quantidade de lasalocida fornecida na mistura correspondeu a $225 \mathrm{mg} / \mathrm{animal} / \mathrm{dia}$ do princípio ativo. A adição de lasalocida sódica não afetou o ganho de peso médio diário ( 0,842 versus $0,852 \mathrm{~kg})$, mas resultou em aumento não-significativo de 7\% na carga animal média (1382 versus $1292 \mathrm{~kg}$ de PV/ha), 6,9\% no ganho de peso vivo por hectare (347,80 versus $325,50 \mathrm{~kg}$ de PV/ha) e $6 \%$ na eficiência alimentar (8,56 versus $9,07 \mathrm{~kg} \mathrm{MS} / \mathrm{kg}$ PV), aumentou o custo de utilização da pastagem em R $\$ 11,50 / \mathrm{ha} \mathrm{e} \mathrm{propiciou}$ incremento na receita líquida em $\mathrm{R} \$ 15,30 / \mathrm{ha}$.
\end{abstract}

Palavras-chave: carga animal, custo, desempenho animal, eficiência alimentar, ionóforo, receita líquida

\section{Lasalocid Added to Salt for Beef Heifers Grazing Annual Temperate Grasses}

\begin{abstract}
The experiment was conducted to evaluate the performance of beef heifers with average age of ten months and average initial weight of $200 \mathrm{~kg}$, grazing cultivated annual temperate grasses mixtures supplemented with salt plus lasalocid or salt. Spread sowing ocurred on 04/21/95, being the area fertilized with $200 \mathrm{~kg} / \mathrm{ha}$ of $05-30-15$. Nitrogen fertilization in the form of urea $(175 \mathrm{~kg} / \mathrm{ha}$ of N) was subdivided in four applications. The establishment of the pasture occured from $04 / 21$ to $06 / 08$ and the experimental period occured from 09/08 until 11/14. Salt and salt plus lasalocid were supplied weekly. Quantity of lasalocid supplied in the mixture was $225 \mathrm{mg} / \mathrm{animal} /$ dia. Addition of lasalocid did not affect average daily weight gain (.842 vs $.852 \mathrm{~kg}$ ), but resulted in a no significant increase of $7 \%$ in stocking rate (1382 vs $1292 \mathrm{~kg} / \mathrm{ha}), 6.9 \%$ increase in weight gain per ha (347.8 vs $325.5 \mathrm{~kg}$ ), $6 \%$ better feed efficiency ( $8.56 \mathrm{vs} 9.07 \mathrm{~kg}$ $\mathrm{DM} / \mathrm{kg}$ of live weight gain), and increased cost of pasture utilization in $\mathrm{R} \$ 11.50 /$ ha providing an increment in net income of $\mathrm{R} \$ 15.30 / \mathrm{ha}$.
\end{abstract}

Key Words: animal performance, cost, feed efficiency, ionophore, net income, stocking rate

\section{Introdução}

Visando amenizar o déficit alimentar do período compreendido como vazio forrageiro do outono-inverno, em que o campo nativo não apresenta crescimento suficiente para suportar adequadamente o número de animais que suporta no verão, são largamente utilizadas pastagens cultivadas de estação fria, no Rio Grande do Sul. Vários trabalhos com animais em pastejo têm demonstrado o elevado potencial produtivo destas espécies quando utilizadas e manejadas adequadamente, RESTLE et al. (1998, 1999a), LUPATINI et al. (1999), ROSO et al. (1999), ROSO et al. (2000) e ROSO e RESTLE (2000).

As forrageiras anuais de inverno, como a aveia, o azevém e o triticale apresentam, durante a fase de crescimento, alta qualidade nutricional. O teor de proteína destas forrageiras é superior aos valores preconizados pelo NATIONAL RESEARCH COUNCIL - NRC (1996) para propiciar elevados ganhos de peso (LUPATINI et al., 1997). Também a digestibilidade da matéria orgânica é elevada, podendo ultrapassar o nível de 70\% (RESTLE et al., 1998). No entanto, o elevado conteúdo de água que estas forrageiras apresentam na fase de crescimento limita o consumo de matéria seca pelo animal, podendo o consumo de energia ser insuficiente para atender as exigências energéticas para os animais expressarem seu potencial máximo de ganho de peso.

Os ionóforos são aditivos empregados para melhorar a eficiência de utilização dos alimentos consumidos pelos animais. A lasalocida sódica é um ionóforo

\footnotetext{
${ }^{1}$ Engenheiro-Agrônomo, Mestre em Zootecnia, PROGEPEC Consultores Associados Ltda.

2 Engenheiro-Agrônomo, Ph.D., Pesquisador do CNPq, Professor Titular, Departamento de Zootecnia da UFSM, CEP: $97119-900$ Santa Maria - RS. E.mail: jrestle@ccr.ufsm.br Fone: (55)220-8084.
} 
com ação sobre a população microbiana do rúmen, alterando as proporções finais de ácidos graxos voláteis, principalmente, pelo aumento na proporção de ácido propiônico e pela diminuição dos ácidos acético e butírico (THONNEY et al., 1981). Esta alteração é benéfica, pois o ácido propiônico é energeticamente mais eficiente, além de reduzir as perdas de metano associadas à produção dos ácidos acético e butírico. Os ionóforos tem demonstrado consistentes respostas positivas na eficiência alimentar para animais em confinamento (BERGER et al., 1981; GOODRICH et al., 1984), sendo facilmente adicionados ao concentrado. No entanto, os trabalhos de pesquisa e as informações geradas sobre o uso da lasalocida sódica para animais mantidos em pastagem são em pequeno número, principalmente pelas dificuldades na forma de sua utilização quando não são utilizados suplementos energéticos e/ou protéicos.

THOMAS (1998) recomenda o uso de ionóforos a fêmeas de reposição desde o nascimento até o primeiro parto. No entanto, os trabalhos de pesquisa mostram que o uso de ionóforos fornecidos via suplemento para animais em pastagem tem apresentado resultados variados. OLIVER (1975) observou maior ganho de peso para animais mantidos em capimbermuda que recebiam lasalocida no suplemento, resultados semelhantes aos relatados por POTTER et al. (1976), fornecendo monensina no suplemento. No entanto, ANDRADE et al. (1996) e mais recentemente RESTLE et al. (1999b), fornecendo, respectivamente, monensina associada ao suplemento mineral e lasalocida associada ao suplemento energético, não verificaram influência no ganho de peso, para animais mantidos em pastagem. Apesar de não verificarem efeito benéfico da monensina no ganho de peso, UTLEY et al. (1978) observaram que a adição do ionóforo resultou em melhor eficiência de utilização da pastagem, com o aumento da carga animal.

De maneira geral, os trabalhos de pesquisa que estudaram o uso de ionóforos para animais mantidos em pastagem avaliaram apenas o ganho de peso/ animal, não estudando os seus efeitos na carga animal/ha e no ganho de peso/ha.

Este trabalho foi conduzido com objetivo de determinar a influência da adição de lasalocida sódica ao sal comum no ganho de peso médio diário, ganho de peso/ha, carga animal/ha e eficiência de transformação de pasto em ganho de peso de fêmeas de corte mantidas em pastejo contínuo em pastagem cultivada com gramíneas anuais de estação fria, bem como avaliar a sua resposta econômica.

\section{Material e Métodos}

O experimento foi conduzido no Departamento de Zootecnia da Universidade Federal de Santa Maria, na Depressão Central do Rio Grande do Sul. O solo é classificado como Podzólico vermelho-amarelo, pertencendo à unidade de mapeamento São Pedro e o clima da região é cfa (subtropical úmido), conforme classificação de Köppen (MORENO, 1961).

Foram utilizados seis piquetes com área de 1 ha cada, com pastagem composta pela mistura de aveia preta, triticale e azevém. A semeadura a lanço foi realizada no dia 21/04/95 utilizando 35,70 e $35 \mathrm{~kg} / \mathrm{ha}$ de semente de aveia preta cv. comum (Avena strigosa), triticale cv. CEP 23 (X Triticosecale) e azevém cv. comum (Lolium multiflorum), respectivamente. Adubação de base seguiu as Recomendações de Adubação para o Estado do Rio Grande de Sul, sendo utilizados 200/ha da fórmula 05-30-15 e na adubação de cobertura utilizaram-se $175 \mathrm{~kg}$ de nitrogênio/ha, sendo parcelada em quatro aplicações durante todo o ciclo da pastagem. O método de pastejo foi o contínuo com lotação variável, utilizando a técnica de put and take(MOTT e LUCAS, 1952), com oferta estimada de forragem de $10 \mathrm{~kg}$ de matéria seca para cada $100 \mathrm{~kg}$ de peso vivo. A massa de forragem da pastagem foi avaliada nas datas de 08/09, 06/10,03/11 e 15/11, com o corte rente ao solo de 10 amostras $\left(0,25 \mathrm{~m}^{2}\right)$ por piquete. Após a homogeneização, foi composta uma amostra final, em cada avaliação, para determinação do teor de matéria seca (MS), teor de proteína bruta (PB) e digestibilidade in vitro da matéria seca (DIVMS) por piquete. A taxa de acúmulo de matéria seca foi avaliada com o uso de três gaiolas de exclusão ao pastejo por piquete, através da equação descrita por CAMPBELL (1966).

Os animais utilizados foram fêmeas com idade média de 10 meses pertencentes aos grupos genéticos Charolês, Nelore e suas cruzas, com peso médio inicial de $200 \mathrm{~kg}$. Cada piquete continha três animais testers, que mediam o ganho de peso médio diário e um número variável de reguladores, conforme a variação da massa de forragem e da taxa de acúmulo de matéria seca. As pesagens dos animais foram realizadas nas datas de 08/09,06/10, 03/11 e 15/11, após jejum de 6 horas.

O ganho de peso médio diário (GMD) dos animais foi obtido pela diferença entre o peso final e inicial dos animais testers em cada período experimental, dividido pelo número de dias do período. A carga animal por 
832 Rev. bras. zootec.

período foi calculada pelo somatório do peso médio dos animais "testers", com o peso médio dos reguladores multiplicado pelo número de dias que os últimos permaneceram na pastagem, dividido pelo número de dias do período de pastejo, sendo expressa em $\mathrm{kg}$ de peso vivo/ha.

O início do pastejo ocorreu no dia 10/06 e, a partir de $08 / 09$ até $15 / 11$, os animais de três piquetes receberam lasalocida sódica misturada ao sal, enquanto os animais dos três piquetes restantes receberam apenas sal comum. A pastagem foi manejada de forma semelhante nos dois tratamentos, sendo composta por $3 \%$ de aveia, $5 \%$ de triticale, $68 \%$ de azevém e $22 \%$ de material morto no início e por $40 \%$ de azevém e $60 \%$ de material morto no final do período experimental.

A estimativa da eficiência de utilização da MS foi obtida pelo somatório da produção de MS do período experimental e da massa de forragem inicial, subtraindo a massa de forragem do final do período experimental, dividido pelo ganho de peso vivo/ha.

O custo da pastagem correspondente ao período experimental (68 dias) foi calculado em função do número total de dias de utilização da pastagem (158 dias) e do custo total da mesma, em que se incluíram os gastos com mecanização, adubação de manutenção e nitrogenada, sementes e sal comum.

Durante um período de 10 dias antecedendo o período experimental, foi avaliado o consumo voluntário de sal comum, que correspondeu a $0,0125 \%$ do peso vivo ou $25 \mathrm{~g} / \mathrm{animal} / \mathrm{dia}$. A partir desta informação, foi adicionada ao sal lasalocida sódica, visando fornecer 1,5 g/animal/dia (225 mg de princípio ativo). Semanalmente, os cochos foram esvaziados e renovado o suplemento.
Os dados foram analisados pelo método dos quadrados mínimos (SAS, 1990). Foi utilizado o teste de comparações de médias, com base no método dos quadrados mínimos (SAS, 1990), a 5\% de significância. O delineamento experimental utilizado foi o inteiramente casualizado, com três repetições

\section{Resultados e Discussão}

Na Tabela 1 são apresentadas as principais variáveis avaliadas na pastagem.

Observa-se que a taxa de acúmulo de MS, o teor de PB e a DIVMS foram semelhantes entre os tratamentos, concordando com o fato de o manejo adotado nas pastagens de todos os piquetes ter sido idêntico, visando dar as mesmas condições de alimentação aos animais dos dois tratamentos estudados. A massa de forragem média do período experimental ficou acima de $1900 \mathrm{~kg}$ de MS/ha, valor considerado satisfatório, sendo semelhante aos registrados em vários trabalhos (LUPATINI et al., 1998; RESTLE et al., 1998). A massa de forragem ideal em pastagem cultivada de estação fria varia em função das espécies que compõem a mistura, do período de pastejo dentro do ciclo das espécies e dos objetivos propostos dentro do sistema de produção, para que se trabalhe sempre dentro de uma faixa ótima de produção animal e de forragem, visando a maximização da produção por unidade de área.

A qualidade da forragem, expressa pela DIVMS e pelo teor de PB é considerada satisfatória, semelhante aos resultados obtidos por ROSO et al. (1999), ROSO et al. (2000), no final do ciclo das pastagens. O pastejo seletivo deve ter permitido aos animais consumirem forragem de qualidade superior à aquela

Tabela 1 - Médias para massa de forragem (MF), taxa de acúmulo de MS, digestibilidade in vitro da matéria seca (DIVMS) e proteína bruta $(\mathrm{PB})$ da pastagem de gramíneas anuais de estação fria, submetidas ao pastejo com fêmeas e suplementadas com sal associado ou não à lasalocida sódica

Table 1 - Means for forage mass (FM), herbage accumulation rate, in vitro dry matter digestibility (IVDMD) and crude protein (CP) of annual temperate grasses mixture under grazing with heifers supplemented with salt plus lasalocid or salt

\begin{tabular}{|c|c|c|c|c|}
\hline $\begin{array}{l}\text { Tratamento } \\
\text { Treatment }\end{array}$ & $\begin{array}{c}\mathrm{MF} \mathrm{kg} \text { de MS/ha } \\
\quad F M \mathrm{~kg} \mathrm{DM/ha}\end{array}$ & $\begin{array}{c}\text { Taxa de acúmulo } \\
\text { (kg de MS/ha/dia) } \\
\text { Accumulation rate } \\
\text { (kg DM/ha/day) }\end{array}$ & $\begin{array}{l}\text { DIVMS }(\%) \\
I V D M D \%\end{array}$ & $\begin{array}{l}\mathrm{PB}(\%) \\
C P(\%)\end{array}$ \\
\hline $\begin{array}{l}\text { Sal + lasalocida } \\
\text { Salt + lasalocid }\end{array}$ & 1930 & 46,4 & 54,35 & 16,35 \\
\hline $\begin{array}{l}\text { Sal } \\
\text { Salt }\end{array}$ & 1990 & 47,7 & 52,02 & 15,61 \\
\hline
\end{tabular}

$\mathrm{P}>0,05(P>05)$. 
obtida na avaliação da massa de foragem total.

Os resultados sobre o desempenho animal são apresentados na Tabela 2 . O consumo de sal durante o período experimental foi semelhante entre os tratamentos e ao que foi observado no período que antecedeu o período experimental.

O GMD das fêmeas suplementadas com lasalocida sódica de $0,842 \mathrm{~kg}$ foi similar ao das que não receberam lasalocida no sal, $0,852 \mathrm{~kg}$. Ganhos de peso semelhantes também foram obtidos por UTLEY et al. (1978) com ou sem a inclusão de ionóforos (monensina sódica) para novilhas em pastagem de azevém suplementadas com milho, por BERGER et al. (1981), que também não encontraram diferença no GMD em animais que receberam ou não ionóforos na dieta, e por RESTLE et al. (1999b), que, usando novilhos em pastagem de aveia mais azevém e suplementados com milho triturado, obtiveram ganhos de 1,457 e 1,577 com ou sem lasalocida sódica, respectivamente. Avaliando a suplementação de monensina sódica via sal mineral para novilhos mantidos em pastagem de colonião, ANDRADE et al. (1996) também não encontraram efeito significativo no ganho de peso dos animais que receberam o ionóforo. Por outro lado, existem trabalhos (POTTER et al., 1976; BOLING et al., 1977; SPEARS et al., 1984) nos quais foram constatados maiores ganhos de peso médios diários em animais suplementados com lasalocida sódica ou monensina sódica em pastagem cultivada quando comparados aos não suplementados.

A produção por animal depende do consumo de matéria seca, do seu valor nutritivo e da eficiência de utilização dos nutrientes ingeridos. Os ganhos obtidos neste experimento podem ser considerados satisfatórios, por se tratar de uma categoria que não apresenta elevado potencial de ganho de peso, conforme evidenciaram RESTLE et al. (1998), ao avaliarem categorias de bovinos de corte, e ainda pelo fato de a pastagem se encontrar no final do ciclo produtivo, em que o valor nutritivo da forragem decresce acentuadamente. Os ganhos obtidos foram semelhantes aos encontrados por RESTLE et al. (1999a) e ROSO e RESTLE (2000), com a mesma categoria animal usada neste experimento.

A taxa de acúmulo de MS diária por ha foi similar nos dois tratamentos (Tabela 1). A carga animal média foi numericamente superior $(\mathrm{P}>0,05)$ no tratamento que recebeu lasalocida sódica (1382 kg contra $1292 \mathrm{~kg}$ de peso vivo/ha), indicando a possibilidade deste tratamento ter apresentado menor consumo de MS por parte dos animais, o que permitiu o aumento na carga animal/ha. Considerando que a carga animal aumentou $6,5 \%$, é de se esperar que o consumo alimentar possa ter decrescido na mesma proporção. GOODRICH et al. (1984), analisando os resultados de 228 testes, encontraram redução média de $6,4 \%$ no consumo de alimentos nos animais que receberam monensina na dieta. Menores consumos de MS por animais que receberam ionóforos também foram constatados por PERRY et al. (1976), POTTER et al. (1976) e BERGER et al. (1981).

A eficiência alimentar estimada dos animais que consumiram lasalocida sódica foi 5,6\% melhor que os animais do tratamento testemunha $(8,56 \mathrm{~kg}$ contra $9,07 \mathrm{~kg}$ de $\mathrm{MS} / \mathrm{kg}$ de PV). Este valor é inferior aos $10 \%$ encontrados por BERGER et al. (1981), com o uso de lasalocida sódica em confinamento de novilhos, e aos $14 \%$ obtidos com novilhos suplementados com milho e monensina sódica em pastagem de azevém, verificados por UTLEY et al. (1978). Nos resultados dos testes

Tabela 2 - Médias para peso inicial (PI), peso final (PF), carga animal (CA), ganho de peso médio diário (GMD), ganho de peso vivo por ha (GPV) e eficiência alimentar (EA) de fêmeas suplementadas com sal associado ou não à lasalocida sódica em pastagem de gramíneas anuais de estação fria

Table 2 - Means for initial weight (IW), final weight (FW), stocking rate $(S R)$, average daily weight gain (ADG), live weight gain/ha (LWG) and feed efficiency (FE) of heifers supplemented with salt plus lasalocid or salt in annual temperate grasses mixture

\begin{tabular}{|c|c|c|}
\hline $\begin{array}{r}\text { Sal n } \\
\text { Salt }\end{array}$ & $\begin{array}{l}\text { nais lasalocida } \\
\text { plus lasalocid }\end{array}$ & $\begin{array}{l}\text { Sal } \\
\text { Salt }\end{array}$ \\
\hline$\overline{\mathrm{PI}, \mathrm{kg}}$ & 199 & 201 \\
\hline$I W, \mathrm{~kg}$ & & \\
\hline $\begin{array}{l}\mathrm{PF}, \mathrm{kg} \\
F W, \mathrm{~kg}\end{array}$ & 256 & 259 \\
\hline $\begin{array}{l}\mathrm{CA}, \mathrm{kg} \mathrm{PV} / \mathrm{ha} \\
S R, \mathrm{~kg} L W / h a\end{array}$ & 1382 & 1292 \\
\hline $\begin{array}{l}\mathrm{GMD}, \mathrm{kg} \\
A D G, \mathrm{~kg}\end{array}$ & 0,842 & 0,852 \\
\hline $\begin{array}{l}\mathrm{GPV}, \mathrm{kg} \mathrm{PV} / \mathrm{ha} \\
L W G, \mathrm{~kg} L W / h a\end{array}$ & 347,80 & 325,50 \\
\hline $\begin{array}{l}\mathrm{EA}, \mathrm{kg} \mathrm{MS} / \mathrm{kg} \mathrm{PV} \\
F E, \mathrm{~kg} \mathrm{DM} / \mathrm{kg} L W\end{array}$ & 8,56 & 9,07 \\
\hline $\begin{array}{l}\text { Custo do tratamento, } \mathrm{R} \$ / \mathrm{ha} \\
\text { Treatment cost, } R \$ / h a\end{array}$ & 11,50 & 0 \\
\hline $\begin{array}{l}\text { Receita bruta adicional, } \mathrm{R} \$ / \mathrm{ha}^{1} \\
\text { Additional gross income, } R \$ / \mathrm{ha}^{1}\end{array}$ & 26,70 & 0 \\
\hline
\end{tabular}

\section{$\mathrm{P}>0,05(P>.05)$.}

Preço do $\mathrm{kg}$ de peso $=\mathrm{R} \$ 1,20$.

Lasalocida $=\mathrm{R} \$ 10,00 / \mathrm{kg}$.

Price per $\mathrm{kg}$ of live weight ( $R \$ 1.20)$.

Lasalocid $=R \$ 10.00 / \mathrm{kg}$. 
analisados por GOODRICH et al. (1984), a eficiência alimentar foi $7,5 \%$ melhor nos animais com monensina na dieta.

O custo total da pastagem foi de $\mathrm{R} \$ 301,60$ para um período de utilização de 158 dias e o custo no período experimental de 68 dias, de $\mathrm{R} \$ 129,80$. A suplementação com lasalocida sódica resultou em um custo adicional de $\mathrm{R} \$ 11,50 /$ ha, totalizando $\mathrm{R} \$ 141,30 / \mathrm{ha}$ na pastagem suplementada com lasalocida sódica. Embora o ganho médio diário tenha sido semelhante, foi verificado no tratamento com lasalocida sódica ganho de peso/ha $6,9 \%$ superior ao testemunha $(347,80 \mathrm{~kg}$ contra $325,50 \mathrm{~kg})$, resultado da maior carga animal/ha suportada pela pastagem, tendo aumentado o ganho de peso vivo/ha em $22,30 \mathrm{~kg}$. Comercializando este ganho a $\mathrm{R} \$ 1,20$ o kg ganho de peso vivo obtido, houve receita líquida adicional de $\mathrm{R} \$ 15,30 / \mathrm{ha}$.

Sabendo das dificuldades na administração de aditivos, principalmente dos ionóforos, a animais em pastejo, onde não há a suplementação no cocho com concentrados para seu fornecimento, a adição de ionóforo na mistura com o sal mostrou ser uma forma viável e prática de fornecimento a animais em pastejo, devido a seu fornecimento aos animais não ser diário. $\mathrm{O}$ fato de o consumo ser limitado pelo sal, o que favorece o consumo adequado do produto, resulta em incremento na eficiência de utilização da pastagem e na receitalíquida.

\section{Conclusões}

O uso da lasalocida sódica via sal, embora não tenha afetado o ganho de peso dos animais, resultou em incremento na receita líquida/ha, causado pelo aumento numérico da carga animal e o ganho de peso/ha.

\section{Referências Bibliográficas}

ANDRADE, V.J., CORDEIRO, J.S., FERREIRA, M.B.D. et al. Monensina na terminação de novilhos mestiços zebu x angus, a pasto. In: REUNIÃO ANUAL DA SOCIEDADE BRASILEIRA DE ZOOTECNIA, 33, 1996, Fortaleza. Anais... Fortaleza: SBZ, 1996. p.23-27.

BERGER, L.L., RICKE, S.C., FAHEY, G.C. 1981. Comparison of two forms and two levels of lasalocid with monensin on feedlot cattle performance. J. Anim. Sci., 53(6):1440-1445.

BOLING, J.A., BRADLEY, N.W., CAMPBELL, L.D. 1977. Monensin levels for growing and finishing steers. J. Anim. Sci., 44:867-871.

CAMPBELL, A.G. 1966. Grazed pastures parameters; I. Pasture dry matter production and availability in a stocking rate and grazing management experiment with dairy cows. J. Agric. Sci., 67:211-216.
GOODRICH, R.D., GARRET, J.E., GAST, D.R. et al. 1984. Influence of monensin on the performance of cattle. J. Anim. Sci., 58(6): 1484-1498.

LUPATINI, G.C., RESTle, J., CERETTA, M. et al. 1998. Avaliação da mistura de aveia preta e azevém sob pastejo submetida a níveis de nitrogênio. Pesq. Agropec. Bras., 33(11):1939-1943.

MORENO, J.A. 1961. Clima do Rio Grande do Sul. Porto Alegre: Secretaria da Agricultura. 41p.

MOTT, G.O., LUCAS, H.L. 1952. The design conduct and interpretation of grazing trials on cultivated and improved pastures. In: INTERNATIONAL GRASSLAND CONGRESS, 6, 1952. Proceedings... Pensylvania, State College Press, 1952. p.1380-1395.

NATIONAL RESEARCH COUNCIL - NRC. 1996. Nutrient requirement of beef cattle. 6.ed. Washington: National Academy Press. 90p.

PERRY, T.W., COOLEY, C.O., RICHARDSON, L.F. et al. 1976. Effect of monensin on beef cattle performance. J. Anim. Sci., 43(3):665-669.

POTTER, E.L., COOLEY, C.O., RICHARDSON, L.F. et al. 1976. Effect of monensin on performance of cattle feed forage. J. Anim. Sci., 43(3):665-669.

RESTLE, J., LUPATINI, G.C., ROSO, C. et al. 1998. Eficiência e desempenho de diferentes categorias de bovinos de corte em pastagem cultivada. R. Bras. Zootec., 27(2):397-404.

RESTLE, J., ROSO, C., SOARES, A.B. 1999a. Produção animal e retorno econômico em misturas de gramíneas anuais de estação fria. Rev. bras. zootec., 28(2):235-243.

RESTLE, J., SOARES, A.B., FERREIRA, M.V.B. et al. 1999b. Suplementação associada com lasalocida para novilhos em terminação em pastagem cultivada de inverno. Ciência Rural, 29(3):555-559.

ROSO, C., RESTLE, J. 2000. Aveia preta, triticale e centeio em mistura com azevém. 2- Produtividade animal e retorno econômico. Rev. bras. zootec., 29(1):85-93.

ROSO, C., RESTLE, J., SOARES, A.B. et al. 2000. Aveia preta, triticale e centeio em mistura com azevém. 1- Dinâmica produção e qualidade de forragem. Rev. bras. zootec., 29(1):75-84.

ROSO, C., RESTLE, J., SOARES, A.B. et al. 1999. Produção e qualidade de forragem da mistura de gramíneas anuais de estação fria sob pastejo contínuo. Rev. bras. zootec., 28(3):459-467.

SAS. 1990. Language reference. Version 6, Cary, NC: SAS Institute Inc., $1042 \mathrm{p}$.

SPEARS, J.W., HARVEY, R.W. 1984. Performance, ruminal and seruns characteristics of steers feed lasalocid on pasture. J. Anim. Sci., 58(2):460-464.

THONNEY, E., HEIDE, K., DUHAIME, D.J. 1981. Growth, feed efficiency and metabolite concentration of cattle feed high forage diets with lasalocid or monensin supplements. J. Anim. Sci., 52(2):427-433.

UTLEY, P.R., NEVILLE JR., W.E., MCCORMICK, W.C. 1978. Monensin fortified corn supplements in combination with testerine-estradiol implants and vaginal devices for finishing heifers on pasture. J. Anim. Sci., 47(6):1239-1242.

Recebido em: 15/05/00 Aceito em: 12/01/01 